\title{
SOLID STATE COMPATIBILITY STUDIES BETWEEN MONTELUKAST SODIUM AND LEVOCETIRIZINE
}

\author{
DUAA SHEHADAHE AGHA, HIND EL-ZIEN* \\ Department of Pharmaceutics and Pharmaceutical Technology, Damascus University, Damascus, Syria. Email: duaaagha88@gmail.com
} Received: 09 October 2017, Revised and Accepted: 14 December 2017

\begin{abstract}
Objective: The aim of this research is to evaluate montelukast (MNT)-levocetirizine (LVZ) incompatibility when they gather in one solid dosage form.

Methods: Both drugs and their binary mixture (2:1) (MNT-LVZ) were subjected to the following condition: $25^{\circ} \mathrm{C} / 60 \% \mathrm{RH}$ and $40^{\circ} \mathrm{C} / 75 \% \mathrm{RH}$ for 14 weeks. Samples were withdrawn and analyzed using stability-indicating high-performance liquid chromatography (HPLC) method at time intervals $(0,1,4,14$ weeks). Further investigations were carried out using differential scanning calorimeter (DSC), Fourier transform infrared (FTIR), and X-ray powder diffraction (XRPD)

Result: On the basis of HPLC results, the degradation percentage of both drugs in binary mixtures was $<10 \%$ indicating no chemical interaction; this was confirmed by all FTIR results except new band $668 \mathrm{~cm}^{-1}$ appeared in the spectrum of the mixture after storing 14 weeks at $40^{\circ} \mathrm{C} / 75 \%$ $\mathrm{RH}$, revealing possible hydrogen bond formed in the mixture. DSC and XRPD revealed possible physical interaction including phase transformation (release the acid form of montelukast and basic form of levocetirizine and sodium chloride in the medium); this may affect dissolution rate and bioavailability.
\end{abstract}

Conclusion: The results obtained from this research gave an evidence to formulate MNT and LVZ in stable fixed-dose combination for the effective treatment of allergic diseases.

Key words: Montelukast, Levocetirizine, Fixed-dose combination, Solid-state incompatibility, High-performance liquid chromatography, Differential scanning calorimeter, Fourier transform infrared, X-ray powder diffraction.

(C) 2018 The Authors. Published by Innovare Academic Sciences Pvt Ltd. This is an open access article under the CC BY license (http://creativecommons. org/licenses/by/4. 0/) DOI: http://dx.doi.org/10.22159/ajpcr.2018.v11i3.22990

\section{INTRODUCTION}

Among the chronic illnesses, allergic diseases (ADs) are increasing in prevalence, reducing patients' quality of life. AD is harmful immunemediated response against harmless environmental substances called allergen [1]. This immune response includes releasing many mediators from mast cells in different stages. One of them is histamine as a preformed mediators releasing in early stage and another one is leukotriene as newly formed lipid-derived mediators in late stage [2], and according to which, tissues are affected with the allergen; the outcome symptoms manifest in one or more of the following ADs: Asthma, allergic rhinitis, food allergy, atopic dermatitis, and anaphylaxis [1]. It is clearly noted that the drugs of choice for management of $\mathrm{AD}$ are antihistamine and leukotriene receptor's antagonist. Levocetirizine (LVZ) is a third-generation, non-sedating $\mathrm{H}_{1}$-antihistamine indicated for treatment of seasonal and perennial allergic rhinitis and skin urticarial [3]; it is used as a Di-hydro chloride form which is known to be white crystal powder and freely soluble in water [3]. Montelukast (MNT) is a selective cystinel-leukotriene receptor antagonist indicated for chronic treatment of asthma and relief of symptoms of allergic rhinitis [4], it's used as a Sodium salt which known to be white to off-white, hygroscopic, light-sensitive, amorphous powder and freely soluble in water [4]. In such chronic cases, there is much interest to use fixed-dose combination (FDC) due to its benefits such as safety and efficacy, patient's compliance, and cost reduce [5]. FDC implies many active ingredients incorporated into single dosage form in fixed ratio [6]. However, incompatibilities between ingredients may occur in mixture as physical or chemical interactions during manufacture and storage. Since MNT-LVZ solid-state mixing is happened, a yellow color appears in the mixture. Preliminary studies about combine MNT and LVZ in single dosage form are done utilizing separation method but without studying the physiochemical solid-state interaction. Hence, the purpose of this study was to predict the type of interaction using thermal and non-thermal methods.

\section{MATERIALS AND METHODS}

Materials

LVZ Di-hydro chloride is from Chempifine (India); MNT sodium is from Ranbaxy (India). All of chemicals were of high-performance liquid chromatography (HPLC) or analytical grade and obtained from Merck (Germany).

\section{Isothermal stress testing}

MNT: LVZ (2:1, w/w) mixture, MNT alone, and LVZ alone were put in open darkness glassy vials and cotton balls were put on the top to prevent water condensate to go into the vials. Set of vials were kept for 14 weeks in controlled stability cabinets for temperature and relative humidity as follows: $25^{\circ} \mathrm{C} / 60 \% \mathrm{RH}$ and $40^{\circ} \mathrm{C} / 75 \% \mathrm{RH}$. The active agent contents were determined using stability-indicating HPLC method at time intervals $(0,1,4,13$ weeks). To determine the physical-chemical drug-drug interaction, Fourier transform infrared (FTIR), differential scanning calorimeter (DSC), and X-ray powder diffraction (XRPD) studies were performed immediately after mix preparation and after 14 weeks of storing in different conditions outlined above.

\section{HPLC analysis of samples}

The drug contents were determined using in-house developed validated stability-indicating HPLC method, utilizing instrument VWR-Hitachi, Germany, equipped with a L-2130 pump and a L-2200 thermostatted column compartment and programmable detector module ultraviolet (UV) Photo diode array). The chromatographic separation was performed on ODS-3 $\mathrm{L}_{1} \mathrm{c}_{18}(4.6 \times 250 \mathrm{~mm}, 5 \mu \mathrm{m})$ column and a mobile 
phase consisting of mixture of $0.05 \mathrm{M}$ ammonium acetate buffer and methanol $(15: 85, \mathrm{v} / \mathrm{v})$; the $\mathrm{PH}$ was adjusted at 3.5 with glacial acetic acid. The mobile phase was pumped at flow rate of $1.5 \mathrm{ml} / \mathrm{min}$ at $25^{\circ} \mathrm{C}$. The injection volume was $20 \mu \mathrm{L}$ and the UV detector was set at a wavelength of $230 \mathrm{~nm}$. Triplicate samples withdrawn at each time intervals were diluted suitably with methanol, and the recovery percentage is calculated.

DSC

DSC analysis was performed on 821e Mettler Toledo, Switzerland. Approximately $5 \mathrm{mg}$ of the samples were weighed directly in the DSC aluminum pan and scanned in the temperature range of $25^{\circ} \mathrm{C}-300^{\circ} \mathrm{C}$ at heating rate of $10^{\circ} \mathrm{C} / \mathrm{min}$ under constant purging of dry nitrogen at $100 \mathrm{ml} / \mathrm{min}$.

\section{FTIR spectroscopy}

FTIR spectra were obtained by using FTIR spectrophotometer (Vector 22, Buker, Germany). Samples were prepared by $\mathrm{KBr}$ disc method. The spectra were scanned over wavenumber range of 500$4000 \mathrm{~cm}^{-1}$.

\section{XRPD}

The physical state of LVZ and MNT in different samples was evaluated using Bruker's D8 Advance diffractometer (Karlsruhe, West Germany). XRPD patterns were recorded using Germanium monochromatic and $\mathrm{Cu}$ radiation with nitrogen filter at voltage of $50 \mathrm{keV}$ and a current of $30 \mathrm{~mA}$. The samples were analyzed over $2 \theta$ range of $3-70^{\circ}$.

\section{RESULTS}

Visual inspection

LVZ is white crystalline powder [7]. Samples of LVZ alone were white powder initially and after 14 weeks in $25^{\circ} \mathrm{C} / 60 \% \mathrm{RH}$ and $40^{\circ} \mathrm{C} / 75 \% \mathrm{RH}$.

MNT is white to off-white powder [8]. Samples of MNT alone were offwhite initially. MNT sample which was stored 14 weeks in $25^{\circ} \mathrm{C} / 60 \%$

Table 1: HPLC results of isothermal stress studies on solid samples

\begin{tabular}{|c|c|c|c|c|c|c|c|}
\hline \multirow[t]{2}{*}{ Sample } & \multirow{2}{*}{$\frac{\text { Initial }}{\text { Assay \% }}$} & \multicolumn{3}{|c|}{$25^{\circ} \mathrm{C} / 60 \% \mathrm{RH}$, Assay $\%$} & \multicolumn{3}{|c|}{$40^{\circ} \mathrm{C} / 75 \% \mathrm{RH}$, Assay $\%$} \\
\hline & & 1 week & 4 weeks & 14 weeks & 1 week & 4 weeks & 14 weeks \\
\hline LVZ alone & $96.49 \pm 1.32 *$ & $96.06 \pm 1.3$ & $95.2 \pm 0.07$ & $97.04 \pm 0.6$ & $95.07 \pm 2.8$ & $95.38 \pm 1.8$ & $95.82 \pm 0.3$ \\
\hline MNT & $102.25 \pm 0.9$ & $95.92 \pm 0.5$ & $95.25 \pm 0.5$ & $96.35 \pm 0.8$ & $91.91 \pm 0.1$ & $92.37 \pm 0.7$ & $90.74 \pm 1.1$ \\
\hline MNT in mix & $100.91 \pm 1.6$ & $95.94 \pm 0.8$ & $94.85 \pm 0.9$ & $96.82 \pm 1.1$ & $92.43 \pm 1.2$ & $90.57 \pm 0.8$ & $91.21 \pm 0.9$ \\
\hline
\end{tabular}

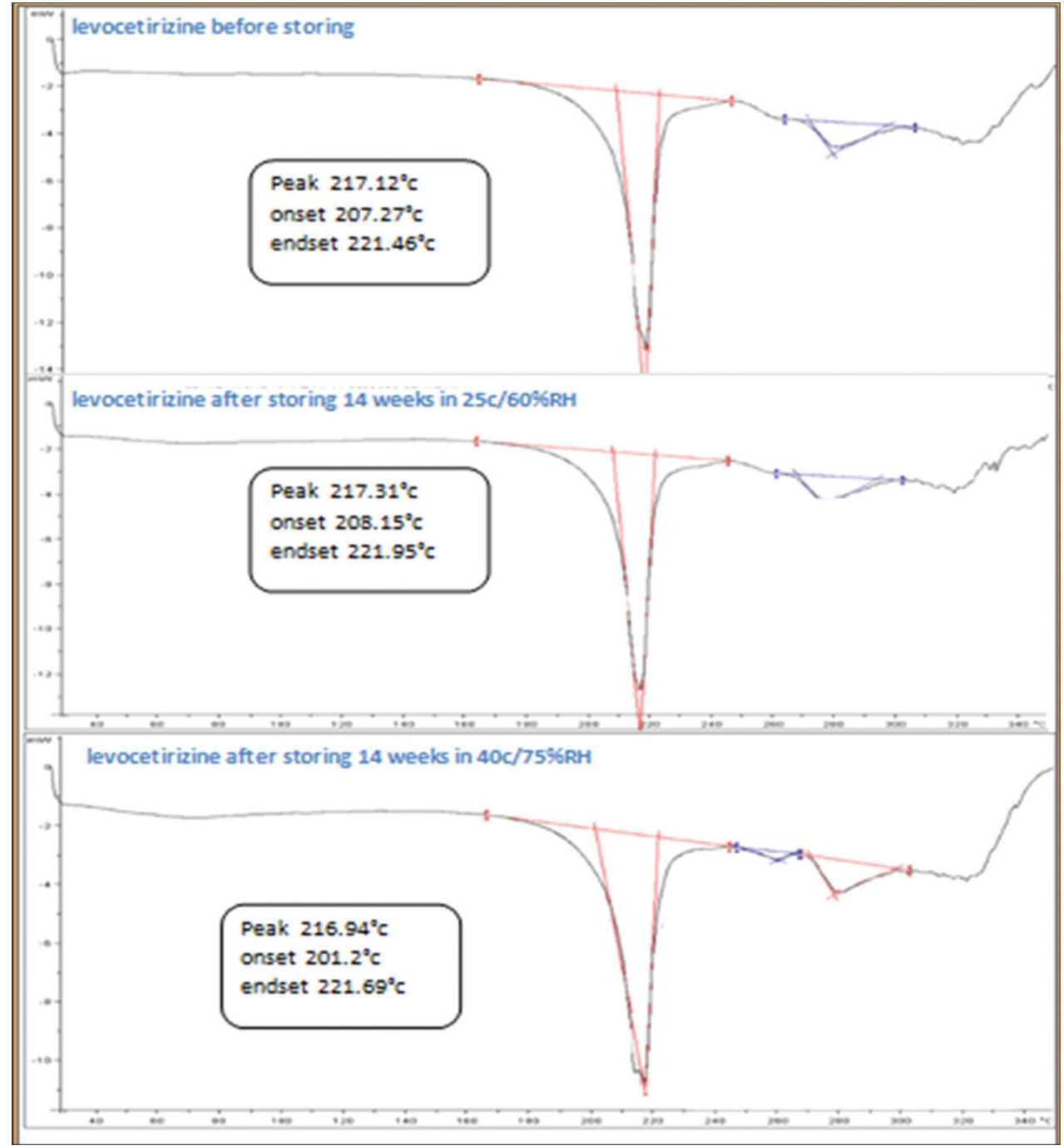

Fig. 1: Differential scanning calorimeter results of levocetirizine before storing, after storing 14 weeks in $25^{\circ} \mathrm{C} / 60 \% \mathrm{RH}$, after storing 14 weeks in $40^{\circ} \mathrm{C} / 75 \% \mathrm{RH}$ 


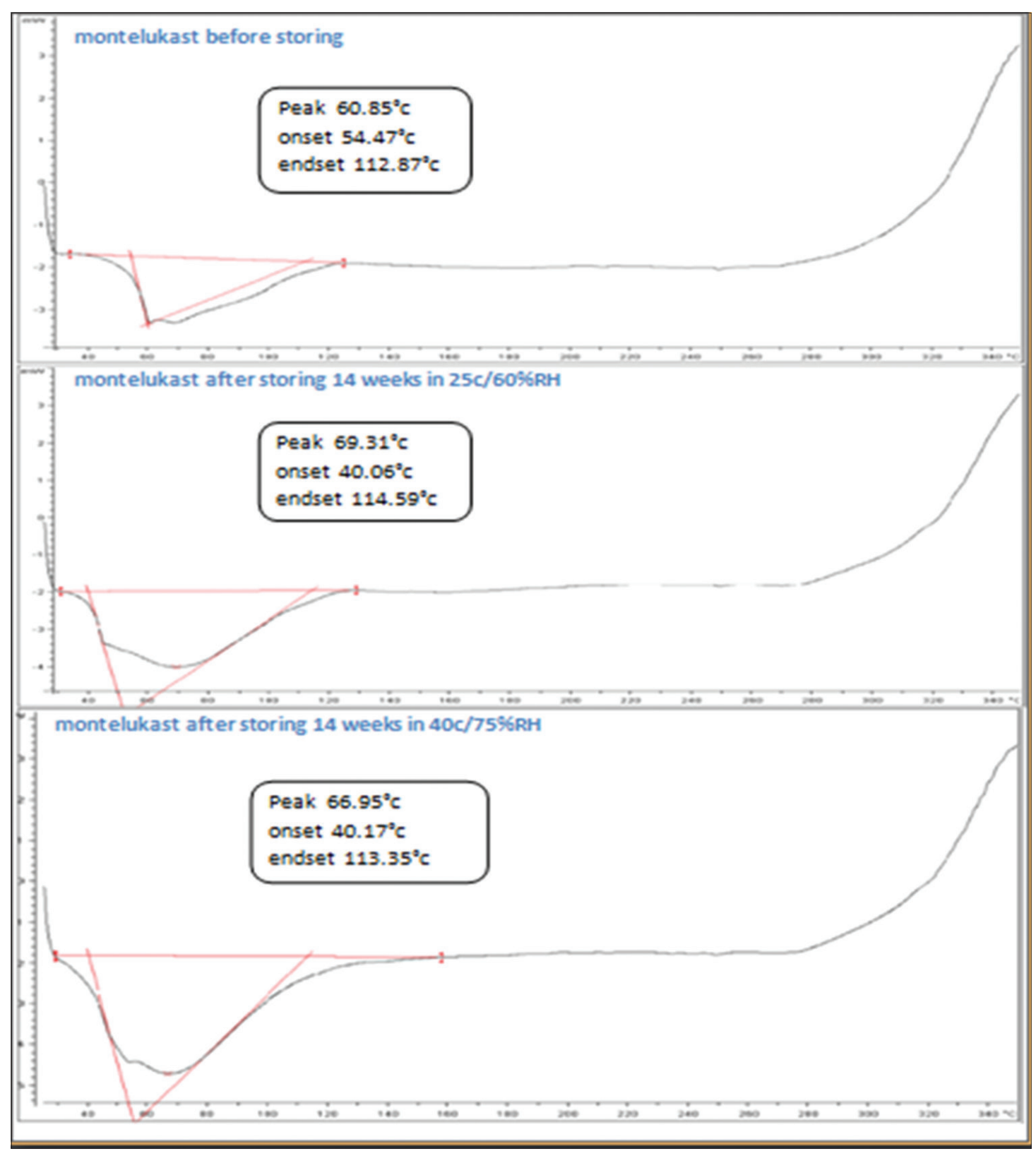

Fig. 2: Differential scanning calorimeter results of montelukast before storing, after storing 14 weeks in $25^{\circ} \mathrm{C} / 60 \% \mathrm{RH}$, after storing 14 weeks in $40^{\circ} \mathrm{C} / 75 \% \mathrm{RH}$

$\mathrm{RH}$, formed an off-white agglomerates. MNT sample which was stored 14 weeks $40^{\circ} \mathrm{C} / 75 \% \mathrm{RH}$, became an one transparent glassy mass; this may be due to the disadvantages of MNT property and its hygroscopicity, it easily absorbs up to 3 equivalent of water [9]. Since MNT and LVZ were mixed in solid state, a yellow color appeared in the mixture, the color intensity increased within time in both conditions $\left(25^{\circ} \mathrm{C} / 60 \% \mathrm{RH}\right.$ and $40^{\circ} \mathrm{C} / 75 \%$ $\mathrm{RH}$ ); this yellow color is perhaps due to desalting of sodium salt of MNT and its transformation to MNT acid which is yellow in color [9], or because of that MNT colors yellow after exposure to the light [10]. Sample of MNTLVZ which was stored in $40^{\circ} \mathrm{C} / 75 \% \mathrm{RH}$ formed agglomerates; this may be due to MNTs' hygroscopicity

\section{HPLC analysis of isothermally stressed samples}

The HPLC analysis of samples is shown in Table 1. The degradation of the drugs in the mixture and each drug alone was found in less than $10 \%$ in different conditions during 1,4 , and 13 weeks. Retention times (LVZ Rt $=2.7 \mathrm{~min}$, MNT Rt $=13.5 \mathrm{~min}$ ) and the shape of peaks did not change in all chromatograms. Furthermore, no additional peak appeared. Hence, the chromatographic analysis provided the evidence that there was no degradation of analytes over storage times. MNT-LVZ mixture was compatible.

\section{DSC results}

The thermograms of LVZ alone initials and after storing 14 weeks in conditions $25^{\circ} \mathrm{C} / 60 \% \mathrm{RH}$ and $40^{\circ} \mathrm{C} / 75 \% \mathrm{RH}$ were shown in Fig. 1 ; it exhibited a sharp endothermic peak with onset at $207^{\circ} \mathrm{C}$, peak at $217^{\circ} \mathrm{C}$, and enthalpy about $177 \mathrm{~J} / \mathrm{g}$ corresponding to melting of pure LVZ following by decomposition of the material, which did not change after storage. The sharp endothermic peaks reflect the crystalline nature of LVZ. The thermograms of MNT alone initials and after storing 14 weeks in conditions $25^{\circ} \mathrm{C} / 60 \% \mathrm{RH}$ and $40^{\circ} \mathrm{C} / 75 \% \mathrm{RH}$ were shown in Fig. 2; it exhibited a broad endothermic peak with a slight shoulder at range about $40-114^{\circ} \mathrm{C}$ corresponding to dehydration of water absorbed by MNT and overlapping with glass transition of amorphous MNT. The enthalpy $(\mathrm{J} / \mathrm{g})$ increased from 80.29 initial to 143 (after 14 weeks in $25^{\circ} \mathrm{C} / 60 \% \mathrm{RH}$ ) and 216 (after 14 weeks in $40^{\circ} \mathrm{C} / 75 \% \mathrm{RH}$ ), resulting from dehydration of addition water amount absorbed by MNT during storing, that was confirmed by Karl Fischer result (data not showed for Karl Fischer). 


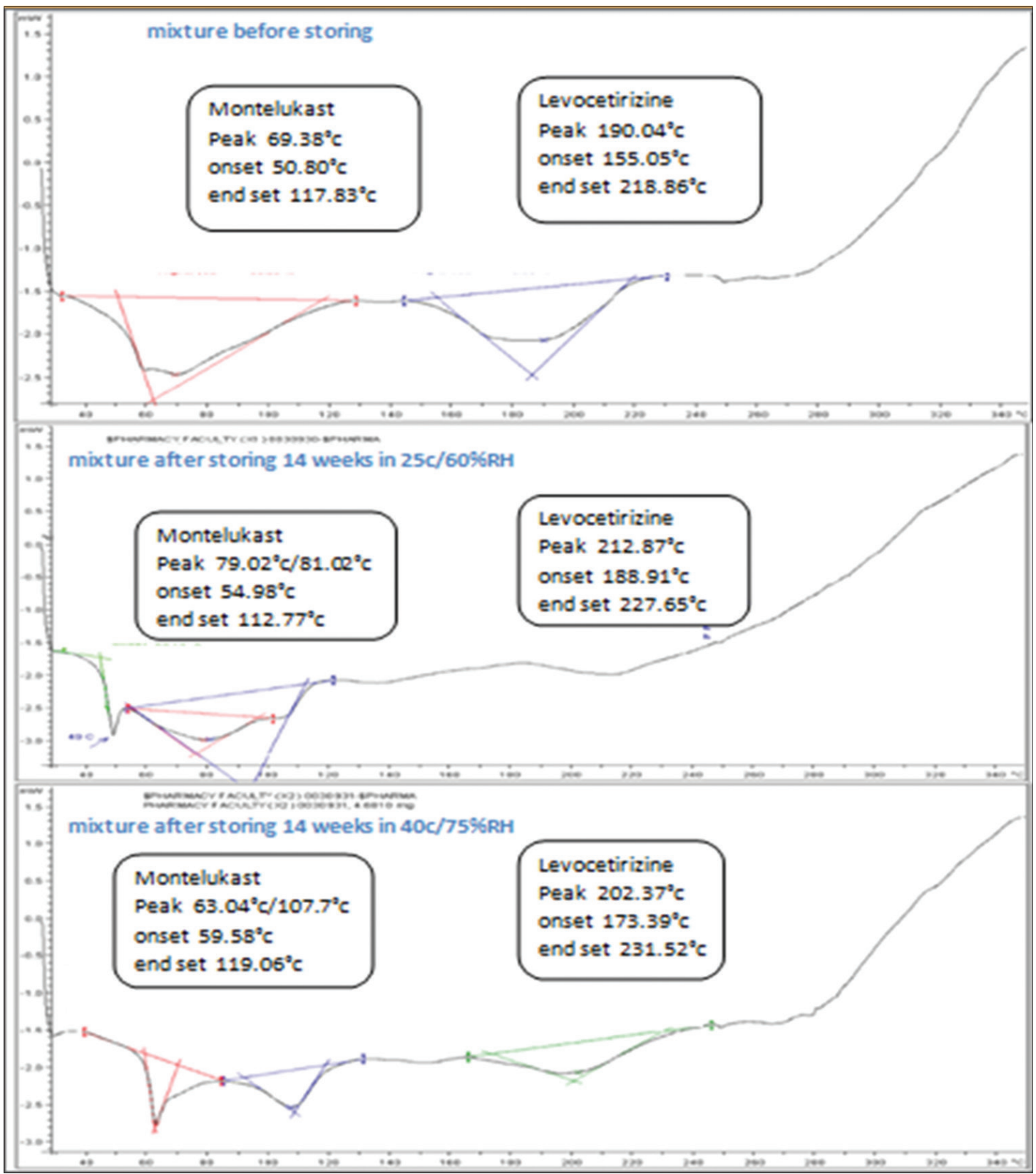

Fig. 3: Differential scanning calorimeter results of mixture before storing, after storing 14 weeks in $25^{\circ} \mathrm{C} / 60 \% \mathrm{RH}$, after storing 14 weeks in $40^{\circ} \mathrm{C} / 75 \% \mathrm{RH}$

The thermograms of MNT-LVZ (2:1) mixture initials and after storing 14 weeks in conditions $25^{\circ} \mathrm{C} / 60 \% \mathrm{RH}$ and $40^{\circ} \mathrm{C} / 75 \% \mathrm{RH}$ were shown in Fig. 3. For LVZ endothermic peak, this peak became broaden and the onset of peak shifted toward lower temperature and the enthalpy of the peak decreased, which indicates reducing in crystallinity [11]; this change could be attributed to the mixing process and impurities maybe water [12] which low the purity of LVZ and does not indicate incompatibility $[13,14]$. For MNT endothermic peak, in the thermograms of mixture, slight changes in temperature ranges and enthalpies were shown initially. After storing for 14 weeks, the peak stayed at the same temperature range but the shoulder began to split to sharp phase in $25^{\circ} \mathrm{C} / 60 \% \mathrm{RH}$ and was more obvious in $40^{\circ} \mathrm{C} / 75 \% \mathrm{RH}$; this may be due to decreasing the amount of water absorbed by MNT, and the initial fast phase is the direct result of dehydration of water from the surfaces of particles [15]

The less water amount absorbed by MNT maybe because of desalting of MNT sodium and converting to MNT acid which differentiates from the sodium salt with its low hygroscopicity [9].

\section{FTIR spectroscopy results}

Pure MNT spectra (Fig. 4a) showed characteristic peaks at $3430 \mathrm{~cm}^{-1}(0-$ $\mathrm{H}$, stretching), 3075, 2970, 2949, $\mathrm{cm}^{-1}$ (C-H, stretching), $2360 \mathrm{~cm}^{-1}$ (S$\mathrm{H}$, stretching), $1594 \mathrm{~cm}^{-1}$ (C=O carboxylate salt, stretching), $1496 \mathrm{~cm}^{-1}$ ( $\mathrm{C}=\mathrm{C}$ aromatic stretching), $1407 \mathrm{~cm}^{-1}$ (O-H tertiary, bending), $761 \mathrm{~cm}^{-1}$ (C-CL, stretching), and $690 \mathrm{~cm}^{-1}$ (C-S, stretching). No changes in the peak positions were observed after exposure to $25^{\circ} \mathrm{C} / 60 \% \mathrm{RH}$ and $40^{\circ} \mathrm{C} / 75 \%$ $\mathrm{RH}$ for 14 weeks as demonstrated by spectra of MNT alone (Fig. $4 \mathrm{f}$ and i), respectively. Pure LVZ spectra (Fig. 4c) showed characteristic peaks at $3430 \mathrm{~cm}^{-1}$ (O-H stretching), $2949 \mathrm{~cm}^{-1}$ (C-H, stretching), $2366 \mathrm{~cm}^{-1}$ (N$\mathrm{H}^{+}$, stretching), $1745 \mathrm{~cm}^{-1}$ ( $\mathrm{C}=0$ carboxylic acid, stretching), $1434 \mathrm{~cm}^{-1}$ (O-H carboxylic acid, bending), 1356,1320 $\mathrm{cm}^{-1}$ (C-H, bending), 1184 $\mathrm{cm}^{-1}$ (N-H tertiary, stretching), $1136 \mathrm{~cm}^{-1}$ (C-O ether, stretching), and 758 $\mathrm{cm}^{-1}$ (C-CL stretching). No changes in the peak positions were observed after exposure to $25^{\circ} \mathrm{C} / 60 \% \mathrm{RH}$ and $40^{\circ} \mathrm{C} / 75 \% \mathrm{RH}$ for 14 weeks as demonstrated by spectra of LVZ alone (Fig. $4 \mathrm{~d}$ and g), respectively. The FTIR spectra of MNT-LVZ mixture initial (Fig. $4 \mathrm{~b}$ ) can be considered as the superposition of individual ones without absence, shift, or intensity 


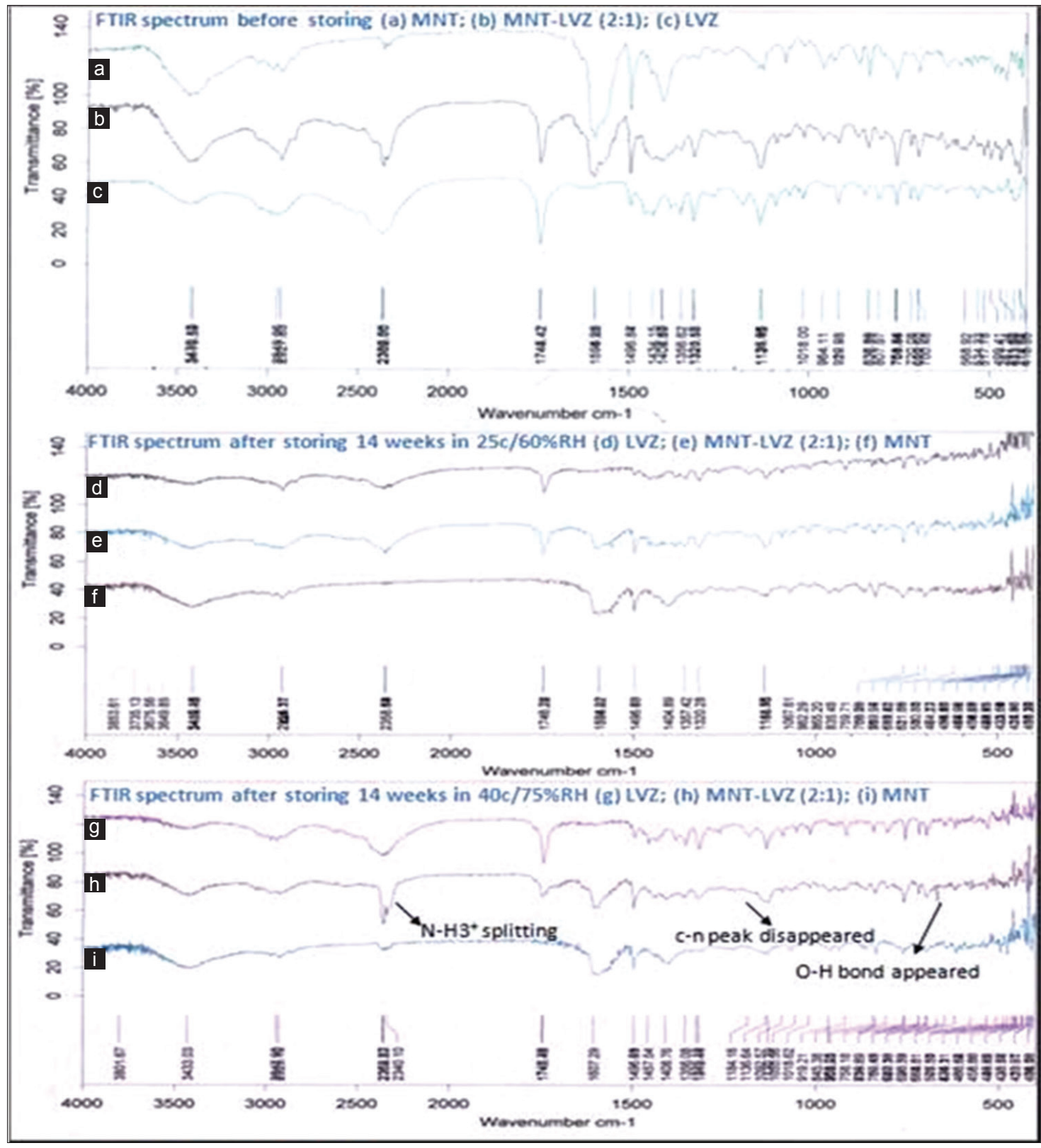

Fig. 4: Fourier transform infrared spectrum of (a) montelukast (MNT), (b) mixture, (c) levocetirizine (LVZ), (d) LVZ after storing 14 weeks in $25^{\circ} \mathrm{C} / 65 \% \mathrm{RH}$, (e) mixture after storing 14 weeks in $25^{\circ} \mathrm{C} / 65 \% \mathrm{RH}$, (f) MNT after storing 14 weeks in $25^{\circ} \mathrm{C} / 65 \% \mathrm{RH}$, (g) $\mathrm{LVZ}$ after storing 14 weeks in $40^{\circ} \mathrm{C} / 75 \% \mathrm{RH}$, (h) mixture after storing 14 weeks in $40^{\circ} \mathrm{C} / 75 \% \mathrm{RH}$, (i) MNT after storing 14 weeks in $40^{\circ} \mathrm{C} / 75 \% \mathrm{RH}$

changes in the vibration bands of MNT or LVZ. Similar observations were seen when mixture stored 14 weeks in $25^{\circ} \mathrm{C} / 60 \%$ RH (Fig. 4e). For the mixture stored 14 weeks in $40^{\circ} \mathrm{C} / 75 \%$ RH (Fig. 4 h), the FTIR spectra exhibited the characteristic peaks of each ones without any shift in frequencies; this indicates no MNT-LVZ interaction [16] but changes in the intensities of $2366 \mathrm{~cm}^{-1}, 1745 \mathrm{~cm}^{-1}, 1594 \mathrm{~cm}^{-1}$, and $1408 \mathrm{~cm}^{-1}$ were observed, and disappearance of $1184 \mathrm{~cm}^{-1}$ (tertiary amine, LVZ) and a new peak at $668 \mathrm{~cm}^{-1}$ were appeared; this may be due to intra and/or inter hydrogen bonding which affect intensity of vibrational modes [16,17]; the small shoulder in the stretching of $\mathrm{N}_{\mathrm{H}}{ }^{3}+\left(2366 \mathrm{~cm}^{-1}\right)$ may be due to the effect of additional water absorbed in the mixture [18].

\section{XRPD results}

The X-ray powder diffractogram of LVZ initial and after 14 weeks of storing in $25^{\circ} \mathrm{C} / 60 \% \mathrm{RH}$ and $40^{\circ} \mathrm{C} / 75 \% \mathrm{RH}$ (Fig. $5 \mathrm{a}-\mathrm{c}$ ), respectively, showed characteristic sharp intensity diffraction peaks at $2 \theta$ values of $7.12^{\circ}, 7.97^{\circ}, 14.44^{\circ}, 14.82^{\circ}, 18.262^{\circ}, 18.59^{\circ}, 20.38^{\circ}, 23.45^{\circ}, 24.22^{\circ}$, $25.15^{\circ}, 25.322^{\circ}$, and $26.194^{\circ}$ which reflected the crystalline nature of LVZ. The X-ray powder diffractogram of MNT initial and after 14 weeks of storing in $25^{\circ} \mathrm{C} / 60 \% \mathrm{RH}$ and $40^{\circ} \mathrm{C} / 75 \% \mathrm{RH}$ (Fig. $5 \mathrm{~d}$-f), respectively, reveals no crystallographic peak just halos suggesting that MNT was amorphous. The X-ray powder diffractogram of MNT-LVZ mixture initial and after 14 weeks of storing in $25^{\circ} \mathrm{C} / 60 \% \mathrm{RH}$ and $40^{\circ} \mathrm{C} / 75 \%$ RH (Fig. 5g-i), respectively, showed characteristic sharp intensity diffraction peaks of LVZ, although their relative intensities were reduced, suggesting reduced degree of crystallinity of LVZ [19] or maybe due to the reducing of LVZ percentage in mixture to half. New sharp diffraction peaks at $2 \theta$ values of $31.665^{\circ}, 45.434^{\circ}$, and 56.426 appeared in mixture stored 14 weeks in different conditions, and their relative intensities were increased in accelerated condition. However, after research, these peaks may belong to sodium chloride salt, as demonstrated in lecture. Sodium chloride salt is produced from desalting of MNT sodium and releasing of sodium ion in media and interacts with hydrochloride ion from LVZ. 


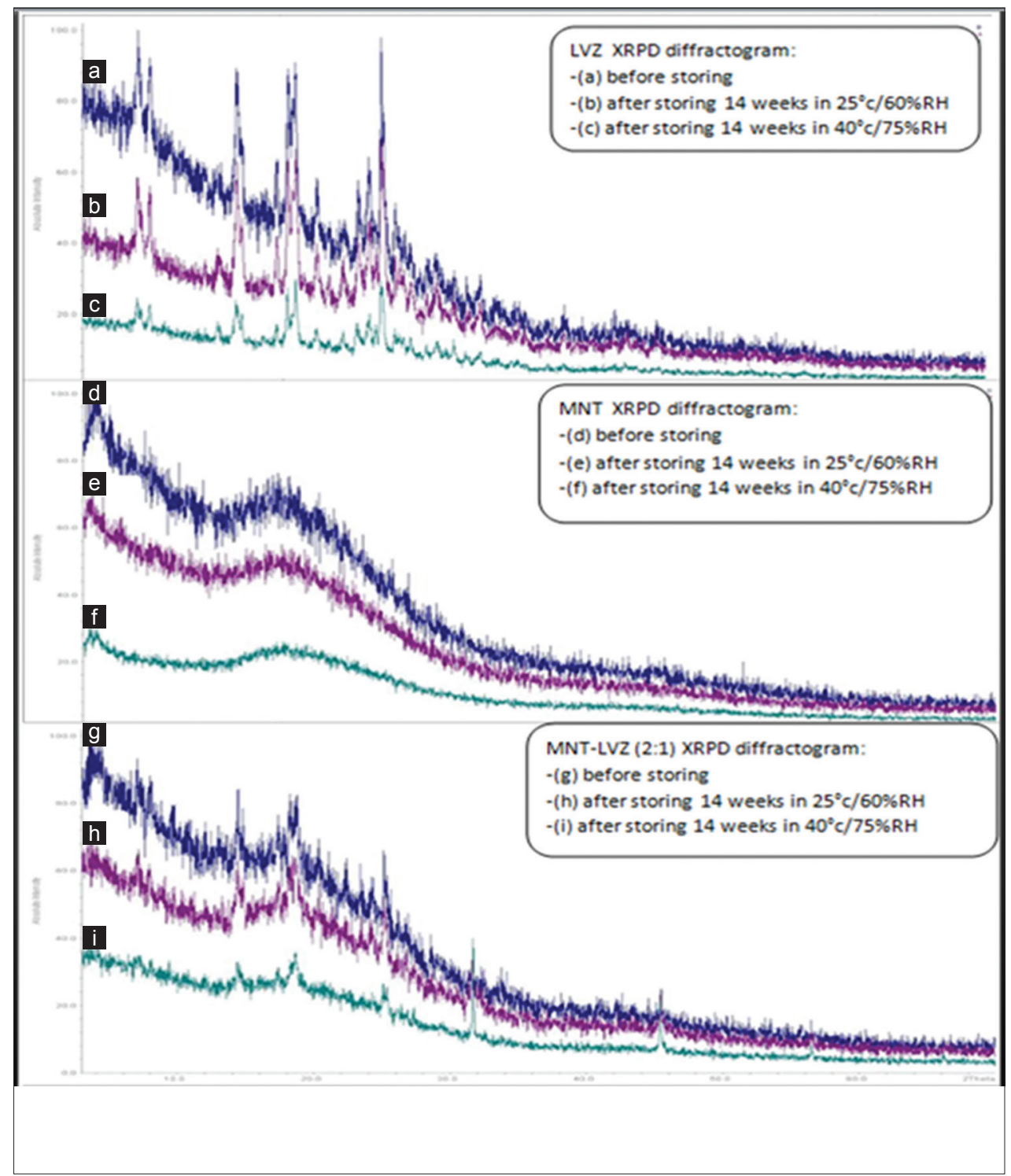

Fig. 5: X-ray powder diffraction of (a) levocetirizine (LVZ), (b) LVZ after storing 14 weeks in $25^{\circ} \mathrm{C} / 65 \% \mathrm{RH}$, (c) $\mathrm{LVZ}$ after storing 14 weeks in $40^{\circ} \mathrm{C} / 75 \% \mathrm{RH}$, (d) montelukast (MNT), (e) MNT after storing 14 weeks in $25^{\circ} \mathrm{C} / 65 \% \mathrm{RH}$, (f) MNT after storing 14 weeks in $40^{\circ} \mathrm{C} / 75 \%$ $\mathrm{RH}$, (g) mixture, (h) mixture after storing 14 weeks in $25^{\circ} \mathrm{C} / 65 \% \mathrm{RH}$, (i) mixture after storing 14 weeks in $40^{\circ} \mathrm{C} / 75 \% \mathrm{RH}$

\section{CONCLUSION}

MNT-LVZ (2:1, w/w) mixture compatibility was studied to form FDC. HPLC analysis results evidenced the chemical stability during storage at $25^{\circ} \mathrm{C} / 60 \%$ RH and $40^{\circ} \mathrm{C} / 75 \%$ RH. FTIR results showed some changes which indicate an interaction related to the formation of hydrogen bonding which is not covalent bonding, and sometimes, it offers the formation of molecular complexes which may improve chemical stability and/ or solubility [16]. DSC and XRPD revealed possible physical interaction arises from the phase transformation including salt and parent conversion which involves the releasing: (1) acidic form of MNT, which characterized with yellow color and its low hygroscopicity, (2) sodium chloride in the medium. This could affect pharmaceutical character like the dissolution rate. Finally, development a FDC of MNT and LVZ is possible, as long as HPLC result confirmed a compatibility between MNT and LVZ, but there is a need to control the pharmaceutical aspects.

\section{AUTHOR CONTRIBUTION}

D.SH.A and H.Z designed the stability study stratigies. D.SH.A performed the experment, collected and analysed the data. D.SH.A wrote the manuscript. H.Z supervised and edited the manuscript.

\section{CONFLICT OF INTEREST}

The authors confirm that they have no conflict of interest.

\section{REFERENCES}

1. Carole $\mathrm{O}$, Tsung-chieh $\mathrm{Y}$. The genetics of asthma and allergic disease: $\mathrm{A}$ $21^{\text {st }}$ century perspective. Natl Ins Health 2012;242:10-30.

2. Stephen J, Mindy T. IgE and mast cells in allergic disease. Natl Ins Health 2013;18:693-704.

3. Saini S, Nanda A, Hooda M, Dhari J. Formulation and evaluation of mouth dissolving anti-allergic tablets of levocetrizine dihydrochloride. J Chem Pharm Res 2011;3:450-5.

4. Merck Research Laboratories. Montelukast, SINGULAIR $\mathbb{R} ; 2016$.

5. Moiz M, Sirnivas P, Mamidi S. Formulation and evaluation of bilayered tablets of montelukast and levocetrizine dihydrochloride Using natural and synthetic polymers. Int J Drug Deliv 2011;3:597-618.

6. Gautam CS, Saha L. Letter to the Editors Fixed dose drug combinations (FDCs): Rational or irrational : A view point. Br J Clin Pharmacol 2007;65:795-6.

7. Pharmaceutica North America I. Material Safety Data Sheet, Levocetirizine Dihydrochloride; 2014.

8. USP. Material Safety Data Sheet, Montelukast Sodium; 2012. p. 1-6. 
9. Arjanne OV, Dennie JM, Den Heavel V. Boxmer, Inventors; Synthon BV, Nijmegen Assignee. Solid-State Montelukast. US Patent No 7,553,853; 2009

10. Montelukast Sodium. Japanese Pharmacopoeia (JP17); 2016. p. 1264-7.

11. Shinde AJ, Misale GM, Salokhe SV. Development and evaluation of bilayer mucoahesive gastroretentive tablet of diltiazem hydrochloride. Int J Pharm Pharm Sci 2014;6:365-70.

12. Gabbott P. A practical introduction to differential scanning calorimetry. In: Principles and Applications of Thermal Analysis. $1^{\text {st }}$ ed. Ames, Iowa: Blackwell; 2008. p. 21-4.

13. Thumma S, Repka MA. Compatibility studies of promethazine hydrochloride with tablet excipients by means of thermal and nonthermal methods. Pharmazie 2009;64:183-9.

14. Tița B, Fuliaş A, Bandur G, Marian E, Tița D. Compatibility study between ketoprofen and pharmaceutical excipients used in solid dosage forms. J Pharm Biomed Anal 2011;56:221-7.
15. Blatchford C, Saunders M, Potluri K, Gaisford S, Buckton G. Assessment of the Re-Crystallisation Behaviour of Micronised AlphaLactose Monohydrate. London, United Kingdom: Pharmaterials Ltd, The London School of Pharmacy.

16. Raju K. FTIR studies of hydrogen bonding interaction between the hydroxyl and carbonyl liquids. Adv Appl Sci Res 2015;6:44-52.

17. Umeda Y, Fukami T, Furuishi T, Suzuki T, Makimura M, Tomono K, et al. Molecular complex consisting of two typical external medicines: Intermolecular interaction between indomethacin and lidocaine. Chem Pharm Bull (Tokyo) 2007;55:832-6.

18. Ghorab M, Gardouh A, Gad S. Effect of viscosity, surfactant typr and concentration on physiochemical properties of solid lipod nanoparticles. Int J Pharm Pharm Sci 2015;7:145-53.

19. Sunil SA, Srikanth MV, Rao NS, Raju V, Murthy KV. Investigation on in vitro dissolution rate enhancement of indomethacin by using a novel carrier sucrose fatty acid ester. Daru 2012;20:4 